\title{
The survey of transport vehicle delays at the traffic light intersections of the urban arterial streets
}

\author{
Oleksandr Stepanchuk, ${ }^{1}$ Andrii Bieliatynskyi, ${ }^{2}$ Olexander Pylypenko ${ }^{3}$ \\ ${ }^{1,2,3}$ National Aviation University, 03058 Kyiv, Ukraine, E-mail: olst@i.ua
}

\begin{abstract}
The survey of traffic light intersections of the Kyiv street network has been analyzed. The certain regularities leading to the delays and traffic difficulties were revealed in results obtained.
\end{abstract}

Keywords: traffic light intersections, average delay of vehicles, queue length.

\section{Actuality of the subject matter}

The interrelation between vehicular and pedestrian traffic in conditions of significant number of traffic light intersections along the urban arterial roads has the certain characteristic regularities, especially in the intersection zones.

Such problem has been extensively studied in many scientific papers for uncontrolled intersections mainly, where the transport flow models have been developed and techniques to obtain necessary accurate data have been proposed. But for signalized intersections such type exact results are very difficult to obtain $[1,2]$.

One of the reasons of such situation is that any vehicular traffic cannot be considered as a stationary process, since it is subjected to periodic changes determined by the length of traffic signal cycle.

\section{Problem solution}

The other reason is that the transport vehicle approaching along arterial road to traffic light intersection is under the significant influence of the upstream traffic light intersections where traffic flows are formed mainly as some compact groups of vehicles called "platoons".

In such conditions, the traffic light intersections even under the perfect traffic light control leads to traffic flow instability such as deceleration, braking, acceleration, stopping, and stopped delay of vehicles.

The delay under the traffic light control occurs when that vehicles arriving to the intersection during red indication must wait the green indication to continue moving.

It should be noted also that the delay at the traffic light intersection within its single cycle consists of two components: the delay during the red phase and the delay during the green phase until the vehicle as a platoon's member starts moving.

Delay of transport vehicle at the traffic light intersection is one of the generally accepted in the world practice functional criteria for assessment of traffic management and traffic control levels.

The purpose of traffic management and traffic control is to minimize the delays and maximize the traffic lanes capacity, accordingly. 
The studies described in [3] confirm that a single vehicle's delay depends on the red phase length, approach time and queue move-up time.

The average delay of vehicles at the signalized intersection depends on the following factors: the length of traffic light cycle, the effective green time, the rate at which the vehicles approach the intersection, the rate at which vehicles in a queue start moving up from the intersection at the green phase, the number of vehicles gathered in a queue before the red phase of the light for drivers occurs.

Nowadays there are a number of known methods (Bekmen, Webster, Newell, McNeill, and others) to determine the transport delays at the signalized intersections of different types. It should be noted that the authors of these papers have made a significant contribution to world science dealing with development and improvement of delay determination models; these models can be used to determine the average delay at a certain signalized intersections and they should be used to implement traffic lights at the intersections and automated traffic control systems.

The objective of our study was to assess how the signalized intersections influence the traffic speed. The study was conducted in three stages:

- determination of the number of forced stops as a consequence of vehicle arrival during the red interval of traffic light;

- determination of the average delay time of vehicle at the signalized intersections where queues do not occur (there is a free mode of traffic);

- determination of the average delay time of vehicle at the signalized intersections where queues has been formed and exists during a long time.

The 568 traffic lights are located on the Kyiv highways network. Therefore, any vehicle route along the Kyiv street network includes, on average, about 10 traffic light intersections. Nowadays, there are different methods of coordinated traffic control on the street network of cities, like green wave, but forced stop of vehicles caused by red signal of traffic light will always be observed. The question naturally arises, how often any vehicle will need to stop at the red signal of the traffic light and how many intersections it will drive without stops.

To answer this question, it was conducted the survey aimed to determine the number of forced stops of vehicles caused by red signal of traffic light with respect to the total number of traffic lights located along the same traffic route. The survey was conducted on the Kyiv street network during 2012-2017. This survey's results are represented on fig.1

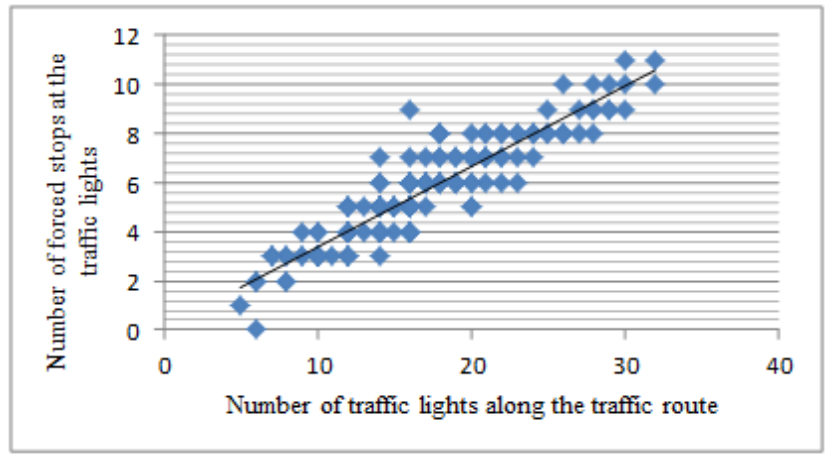

Fig. 1. The correlation field of the number of traffic lights along the traffic routes to the forced stops at them.

The correlation coefficient is: $r=0,917$ 
By the value of the correlation coefficient, it can be concluded that strong connection exists between the number of traffic lights along the vehicle's traffic route and the number of forced stops caused by the red signal of traffic light.

Based on the obtained result and the performed correlation analysis, it was bult the regression model of dependence between the number of traffic lights located along the traffic route and the number of forced stops caused by the red signal of the traffic light.

The regression equation has the form:

$$
y=0,3285 x+0,054
$$

The determination coefficient: $R^{2}=0,845$

The objective of the second stage of the study was to determine the average delay of vehicles at a signalized intersection, which allows determining some optimal extra time necessary to drive through signalized intersections under any traffic conditions.

Regulatory criteria are the average delay and the queue length that occurs at the intersection. Minimization of these two criteria is achieved at the minimum values of the cycle time that are possible under certain traffic conditions.

To determine the delay time of vehicles at the signalized intersection, we use the wellknown technique [3], which allows us to determine the average delay, saturation flow and the intersection efficiency rate.

25 signalized intersection along the Kyiv arterial streets were selected for this survey. All necessary indicators were taken along the most loaded traffic route and each intersection was observed during twenty cycles of traffic lights operation [4].

By analysis of the survey results it was concluded the following:

the average delay per vehicle at signalized intersection is 28.3 seconds that involves two components: the average stopped delay ( 25.4 seconds) caused by arrival of vehicle during the red interval of traffic light and queue move-up time ( 2.9 seconds) taken during the green interval when the queue of vehicles that had formed during the previous red interval has not yet fully dissipated. It should also be noted that the average number of vehicles stopped at the intersection was 12 , while those that drove the intersection without stopping was 16 ;

the average efficiency rate of signalized intersection is 0.57 . But it should be noted that this rate varies significantly at the different intersections, namely: on the arterial roads functioning according to traffic control system's strategy "green wave", it ranges within $0.75-0.80$ on average while on collector roads and even arterial roads without "green wave" control strategy it ranges only within $0.15-0.20$.

It is also necessary to note that according to the data obtained during the survey, the great correlation $(r=0,945)$ was found between the red interval of traffic light and the average delay per vehicle at the intersection at the red signal of the traffic light (fig.2).

By the results of the correlation analysis, the regression model of the dependence between the red interval of traffic light and the average delay per vehicle at the intersection has been deduced:

$$
y=0.602 x+1.47
$$

The determination coefficient $R^{2}=0.892$ 


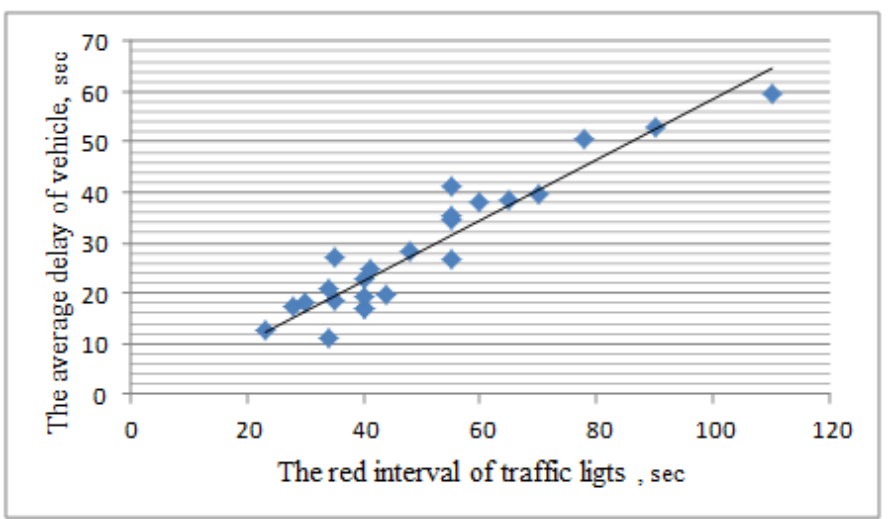

Fig. 2. The correlation field of the red interval of traffic lights.

The analysis of the observation results argues that the presence of traffic lights on the city's street network leads to inevitable time delays.

To study the causes of queue formation at the traffic light intersections along the arterial streets of the Kyiv city, there were used only the intersections where the queues were observed during the whole day. The results of this survey were processed according to the technique [5].

In our case, as an example, for a more detailed analysis of queue formation at traffic light intersections, let's consider the intersection of the O.Teliga and O.Olzhich streets. This intersection is located on the main city street.

The initial data for this intersection consist of the following information: the $\mathrm{T}$ intersection, having six lanes on the Olena Teliga street and two lanes on the Oleg Olzhich street; traffic light cycle is $T_{c}=145 \mathrm{sec}$ with two phase traffic signal operation; the green interval $t_{\text {green }}=105 \mathrm{sec}$; red interval $t_{\text {red }}=34 \mathrm{sec}$; amber interval $t_{\text {amber }}=6 \mathrm{sec}$. The distance between vehicles in the queue along the same lane is accepted $2 \mathrm{~m}$; the estimated vehicle length is $5 \mathrm{~m}$; driver reaction time $\mathrm{t}_{\mathrm{r}}=1 \mathrm{sec}$. To simplify necessary calculations, the total observation time was divided into certain periods of 12 traffic light cycle ( 29 minutes) long each, so the number of vehicles arriving at the intersection was quantified during precisely these time periods, that is, within 29 minutes each. To ease the calculations all survey results are formed in the table. 1 . The first lane of the carriage way was excluded from the calculation for it is assigned for public transport only.

The number of vehicles that haven't driven through the intersection at the end of each period was defined as the difference between the number of vehicles arrived at the intersection during the specified period and the number of vehicles driven through the intersection during the same period. The number of vehicles that haven't driven through the intersection per cycle is defined as the difference between the number of vehicles arrived at the intersection during a specified period and the number of vehicles driven through the intersection for the same period, then dividing the obtained value by the number of traffic light cycles during the same survey period.

The queue length $\mathrm{L}_{\text {queue }}$ at the end of each 12-th cycle was defined as the product of the number of vehicles that haven't driven through the intersection for the current period and the vehicle length, taking into account the distance between vehicles $(7 \mathrm{~m})$. 
Table 1. The main characteristics of queue formation at the intersection according to observation data.

\begin{tabular}{|c|c|c|c|c|c|c|c|c|c|}
\hline 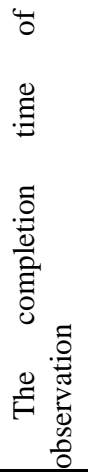 & 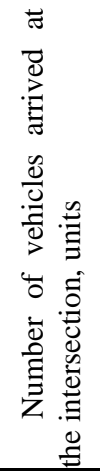 & 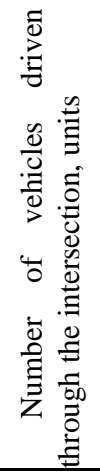 & 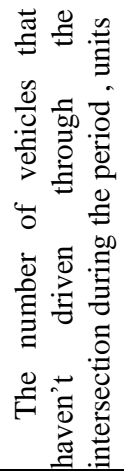 & 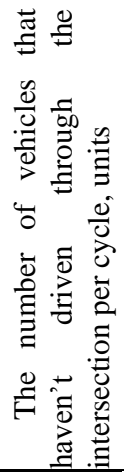 & 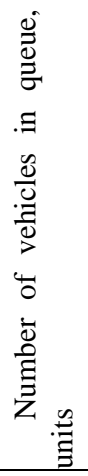 & 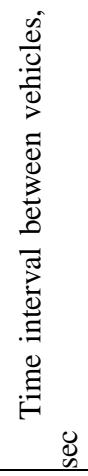 & 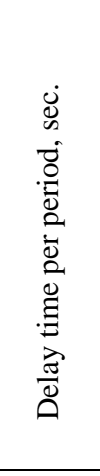 & 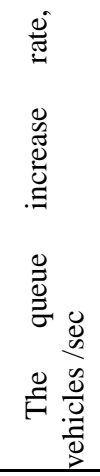 & 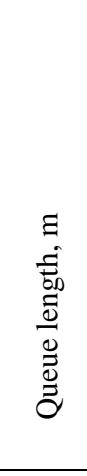 \\
\hline 7:01 & - & - & - & - & - & - & - & - & - \\
\hline $7: 30$ & 948 & 948 & 0 & 0 & 0 & 1,32 & 0,00 & 0,000 & 0 \\
\hline $7: 59$ & 1216 & 1120 & 96 & 8,00 & 96 & 1,11 & 8,91 & 0,055 & 336 \\
\hline $8: 28$ & 1289 & 1125 & 164 & 13,67 & 260 & 1,11 & 15,16 & 0,094 & 910 \\
\hline $8: 57$ & 1254 & 1116 & 138 & 11,50 & 398 & 1,12 & 12,86 & 0,079 & 1393 \\
\hline $9: 26$ & 1163 & 1133 & 30 & 2,50 & 428 & 1,10 & 2,75 & 0,017 & 1498 \\
\hline 9:55 & 1120 & 1174 & -54 & $-4,50$ & 374 & 1,06 & $-4,78$ & $-0,031$ & 1309 \\
\hline 10:24 & 1094 & 1120 & -26 & $-2,17$ & 348 & 1,11 & $-2,41$ & $-0,015$ & 1218 \\
\hline 10:53 & 1029 & 1100 & -71 & $-5,92$ & 277 & 1,13 & $-6,71$ & $-0,041$ & 969,5 \\
\hline 11:22 & 930 & 1026 & -96 & $-8,00$ & 181 & 1,22 & $-9,73$ & $-0,055$ & 633,5 \\
\hline $11: 51$ & 897 & 1003 & -106 & $-8,83$ & 75 & 1,24 & $-10,99$ & $-0,061$ & 262,5 \\
\hline
\end{tabular}

Based on the calculations performed it was found that the maximum quantity of the vehicles arrived at the intersection was at 8:28 and amounts to1289 units (0,741 vehicles/sec), which is on 278 units $(0,066$ vehicles/sec) more than the maximum traffic lane capacity (Fig. 3). With time, the intensity decreases somewhat and at 9:26, it becomes almost equal to the intersection traffic capacity $\left(\mathrm{N}_{\max }\right)$. It is during this period that queue reaches its maximum of 428 units. As the traffic intensity decreases and became lower than the intersection traffic capacity, the queue begins to reduce. Graphically, one can estimate the time period during which the queue fades away. In this case such period is about two hours, - from 9:55 to 11:51 (fig. 4).

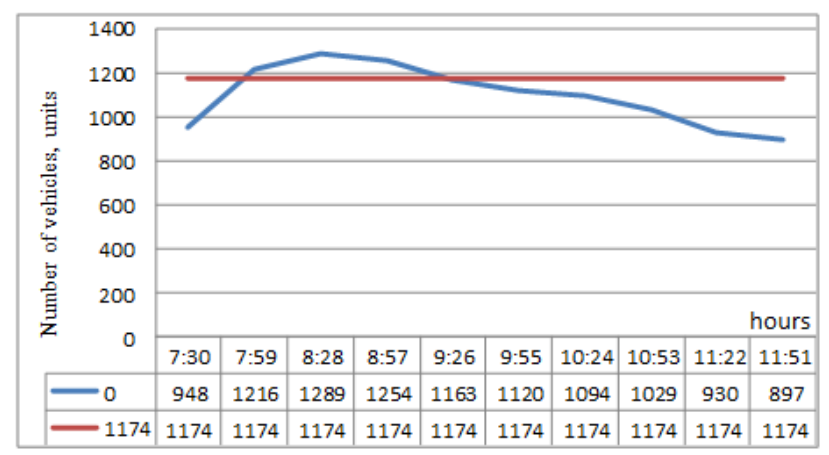

Fig.3. Arrival of vehicles at the intersection during the observation period. 


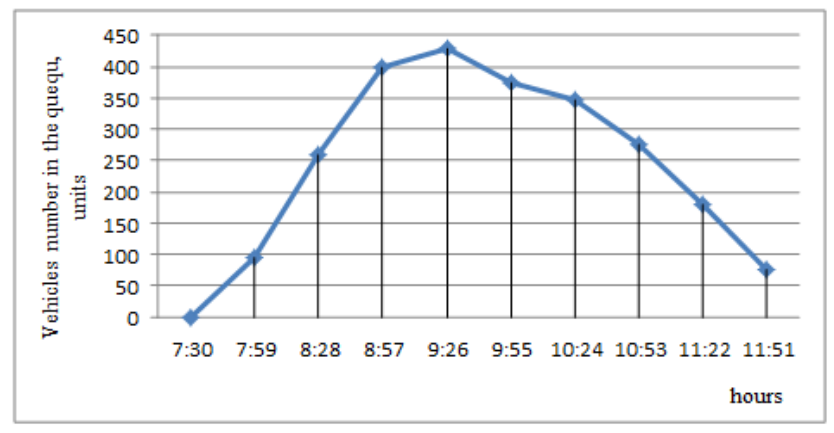

Fig. 4. The number of vehicles in the queue in front of the traffic light.

The crucial factors of the queue formation are the number of vehicles that haven't driven through the intersection during every traffic light cycle, and the time period during which such problem takes place. In this observation, the maximum number of vehicles that had no time to drive through the intersection during one traffic lights cycle, was 14 units, and as such period of intersection overload lasted for a considerable time, so the total length of the queue had increased up to $1498 \mathrm{~m}$.

Thus, the traffic delay at the intersection occurs because number of vehicles arriving at the intersection exceeds its traffic capacity on average 9.4\%. In this case, to eliminate the queue of $1498 \mathrm{~m}$ long completely it is necessary 7.7 minutes even at the condition when another vehicles do not arrive at the intersection at all(fig.5).

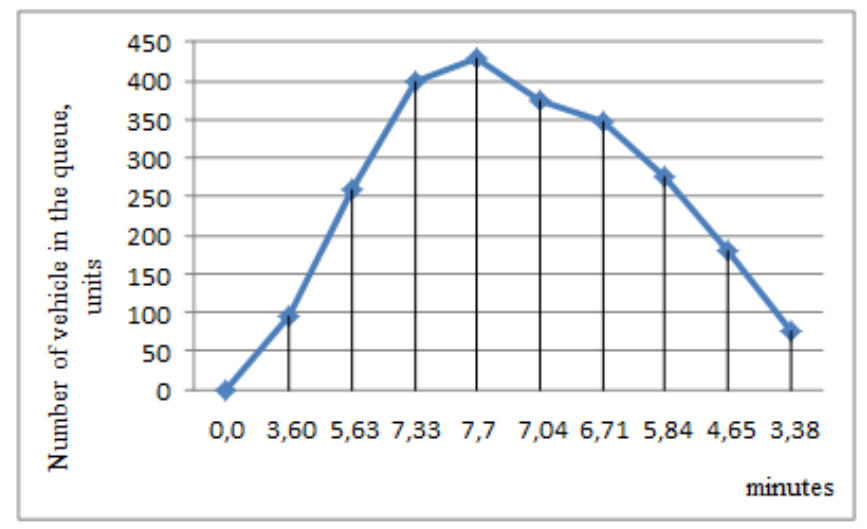

Fig. 5. The number of vehicles in the queue and time of its fading away.

The curve on fig. 5 was approximated by cubic parabola:

$$
y=0,6921 x^{3}-30,28 x^{2}+267,1 x-268,97
$$

The determination coefficient $\mathrm{R}^{2}=0.9636$.

How to solve such type problems was one of the tasks of this survey. In the other words, how much time the transport vehicle requires to overcome the queue at the traffic lights intersection when its traffic capacity doesn't meet the traffic needs and certain traffic congestion has been formed at this intersection already. In this way, there were analyzed all data characterizing the time necessary to overcome the queue depending on its length. By the results of this analysis, it was found that correlation is observed between the time taken 
to arrive at the waiting queue (traffic congestion) at the traffic light intersection and the queue length (Fig. 6).

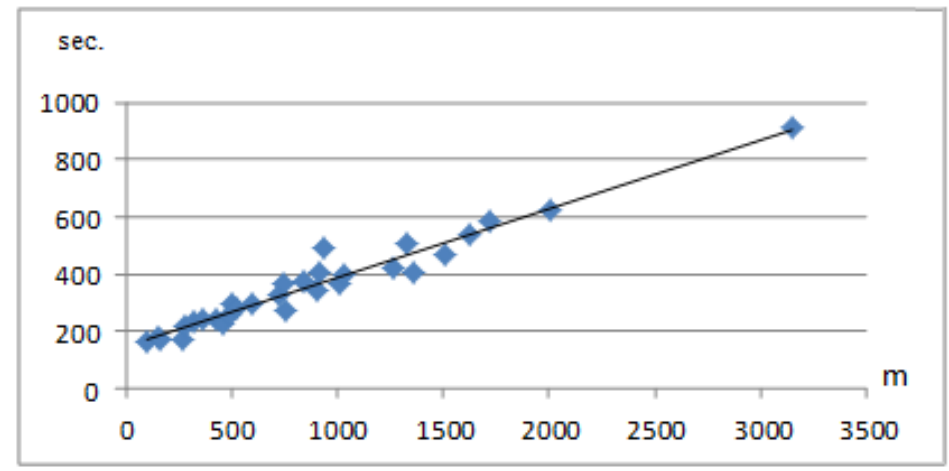

Fig. 6. Dependence between the time required by vehicles queue to travel through the intersection and the queue length.

The correlation coefficient $r=0.976$.

The regression equation:

$$
y=0.241 x+14.8
$$

The determination coefficient $R^{2}=0.954$

\section{Conclusions}

This approach is very important for creating an efficient traffic flow management system because the main the task of traffic flows managment is to minimize the probability of traffic congestion formation at the intersections of urban arteril streets having the "saturated" traffic flow. The purpose of the traffic flow management system is to prevent traffic congestion and, whenever the congestion occurs, to provide possible alternative routes that will enable to redistribute the flows and minimize the time losses because all this are required to determine the effective traffic routes of vehicles. Hence, by applying the approaches analysing above to the system of monitoring and management of traffic flows, it can be determined the expected number of vehicles at the intersections at rush hours and made timely decisions on their redistribution between parallel streets, which, in turn, minimizes the time of traffic delays throughout the city street network.

\section{References}

1. Н. Наумова Теоретические основы и методы управления транспортными потоками средствами мезоскопического моделирования, 331 (2015)

2. Stepanchuk O. Surveying of Traffic Congestions on Arterial Roads of Kyiv City /O. Stepanchuk,

A. Bieliatynskyi, O. Pylypenko, S. Stepanchuk/ Procedia Engineering. 187, pp. 14-21 (2017)

3. Т. Метсон, У. Смит, Ф. Хард. Организация движения, 464 (1960)

4. Є. Рейцен. Організація і безпека міського руху, 454, Київ (2014)

5. О. Бахтина. Разработка методов расчета и оценки заторовых состояний транспортного потока на улично-дорожной сети городов (на примере г. Краснодара), 196 (2006) 